\title{
Rancang Bangun Sistem Klasifikasi Biji Pinang Menggunakan Metode Nearest Mean Classifier Berbasis Android
}

\author{
Andika Firmansyah, Abdullah*, Samsudin \\ Program Studi Sistem Informasi Fakultas Teknik dan Ilmu Komputer Universitas Islam Indragiri \\ Jl. Provinsi parit 1 Tembilahan Hulu Indragiri Hilir Riau \\ *e-mail: abdullah080370@gmail.com
}

(received: 28 Desember 2020, revised: 12 Januari 2021, accepted: 14 Januari 2021)

\begin{abstract}
Abstrak
Pinang (areca catechu) merupakan tumbuhan yang memiliki nilai ekonomis. Buah pinang dikupas kulitnya diolah menjadi biji pinang kering dan selanjutnya dijual ke pengepul. Budidaya pinang mudah dilakukan dan tidak butuh pemeliharaan ekstra dalam perawatannya, sehingga sebagian besar masyarakat di daerah ini senang menjadi petani pinang. Walau bagaimanapun juga penentuan harga biji pinang berdasarkan persentase kekeringan pinang menimbulkan masalah. Penentuan dilakukan sepihak oleh pihak pengepul, dimana dilakukan secara kasat mata sehingga kurang akurat, sehingga berpotensi merugikan pihak petani pinang. Oleh karena itu tujuan penelitian ini adalah membangun sebuah aplikasi sistem cerdas yang dapat membantu dalam mengidentifikasi persentase kekeringan biji pinang. Aplikasi ini berbasis android yang memanfaatkan kamera hand phone yang terdapat di perangkat pintar ponsel android. Penelitian ini akan mencari fitur yang tepat digunakan sebagai pembeda kekeringan antara biji pinang yang satu dengan yang lain. Penelitian ini juga akan mencari algoritma yang tepat untuk melakukan klasifikasi persentase kekeringan biji pinang tersebut. Berdasarkan hasil evaluasi diketahui tingkat akurasi metode Nearest Mean Classifier dalam menentukan kualitas biji pinang adalah sebesar $80 \%$ dengan simpangan baku 7,6. Aplikasi ini diharapkan dapat membantu proses klasifikasi biji pinang dengan lebih cepat, tepat dan akurat dengan memuaskan kedua belah pihak pengepul dan petani. Aplikasi ini juga diharapkan dapat diterima untuk dijadikan alat ukur standar dalam penentuan persentase kekeringan biji pinang sehingga bermanfaat dalam rangka menentukan harga jual biji pinang.
\end{abstract}

Kata Kunci: android, sistem cerdas, klasifikasi, biji pinang

\begin{abstract}
Areca nut (areca catechu) is a plant that has economic value. The peeled areca nut is processed into dried areca nut and then sold to collectors. Cultivating areca nut is easy to do and does not require extra maintenance to maintain, so most people in this area are happy to be areca nut farmers. However, determining the price of areca nut based on the percentage of dryness of the areca nut creates problems. The collectors make the determination unilaterally, which is done in manual so that it is less accurate, so it has the potential to harm the areca nut farmers. Therefore, the aim of this research is to build a smart system application that can help identify the dry percentage of areca nuts. This application is based on android which utilizes a camera device on an android smartphone. This study identify the features that are appropriate to classify areca nuts. This research will also identify the right algorithm to classify the percentage of dryness of the areca nuts. Based on the results of the evaluation, it is known that the accuracy rate of the Nearest Mean Classifier method in determining the quality of areca nuts is $80 \%$ with a standard deviation of 7.6. This application is expected to help the classification process of areca nuts more quickly, precisely and accurately by satisfying both collectors and farmers. This application is also expected to be accepted as a standard measuring tool in determining the percentage of dryness of areca nuts so that it is useful in determining the selling price of areca nuts.
\end{abstract}

Keywords: android, areca nuts, classification, intelligent system 


\section{Pendahuluan}

Sumber daya alam yang dimiliki Indonesia sangat besar, hal ini dikarenakan Indonesia dilewati oleh garis khatulistiwa sehingga selalu disinari oleh matahari sepanjang tahun. Banyak flora dan fauna yang hidup di negeri ini. Pohon pinang (areca catechu) tumbuh subur hampir merata di seluruh wilayah Indonesia [1]. Biji pinang sangat diminati baik dalam negeri maupun luar negeri, hal ini dikarenakan pohon pinang memiliki nilai ekonomis antara lain dapat digunakan sebagai bahan pembuat sirup, pewarna pada tekstil, pemanfaatan dibidang kesehatan dan lain sebagainya [2][3].

Besarnya potensi ekonomi yang dimiliki biji pinang, membuat masyarakat mulai melirik usaha dengan menanam pinang untuk meraih keuntungan. Namun, bagaimanapun juga harapan masyarakat mendapatkan keuntungan yang maksimal, terkendala oleh penentuan persentase kekeringan biji pinang tersebut. Pada umumnya penentuan persentase biji pinang selama ini dilakukan secara visual berdasarkan warna dengan tenaga manusia [4]. Penentuan persentase kekeringan biji pinang ini dilakukan oleh pihak pengepul sehingga rawan terjadi kecurangan dan berpotensi merugikan petani pinang. Permasalahan ini sangat penting dikarenakan persentase kekeringan biji pinang berdampak pada harga jual.

Objek penelitian ini dibatasi pada biji pinang yang diperoleh di kawasan daerah kabupaten Indragiri Hilir. Biji pinang adalah biji pinang kering yang telah dibelah dan dikupas dari kulitnya yang dapat dilihat seperti pada Gambar 1.

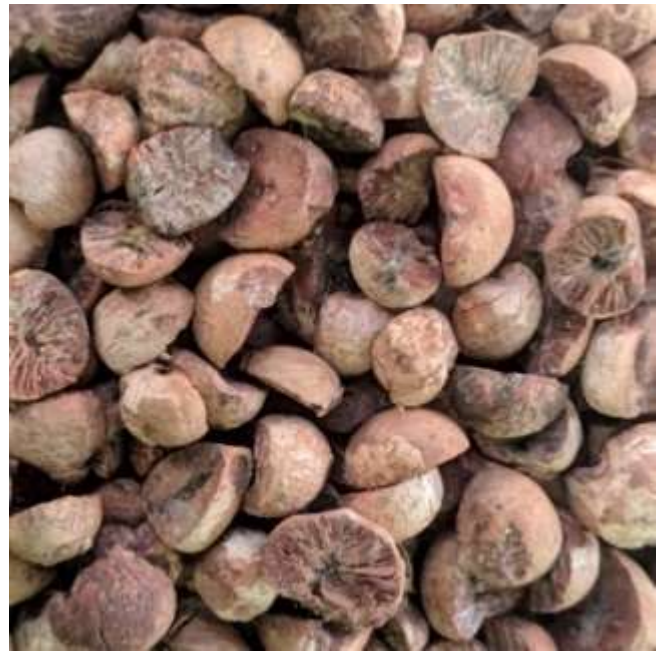

Gambar 1. Biji Pinang Kering

Saat ini, kemajuan teknologi informasi memungkinkan untuk diterapkan dalam pengidentifikasian tingkat kekeringan biji pinang secara efektif dan efisien. Dengan adanya kemajuan teknik pengolahan citra digital yang didukung oleh konsep pengenalan pola, diharapkan klasifikasi biji pinang berdasarkan persentase tingkat kekeringannya menggunakan bantuan ponsel pintar android dapat direalisasikan. Untuk mendapatkan solusi dari permasalahan di atas akan dibangun sebuah aplikasi berupa sistem cerdas berbasis android yang dapat menentukan persentase kekeringan biji pinang ke dalam tingkat kekeringan tertentu. Sistem tersebut diharapkan mampu melakukan klasifikasi biji pinang ke dalam kelas A (kadar air $\leq 5 \%$ ), kelas B (kadar air antara 6\%-11\%) dan kelas C (kadar air diatas $\geq 12 \%$ ). Beberapa model atau algoritma klasifikasi akan diteliti untuk diterapkan pada kasus ini untuk mengetahui model atau algoritma yang memberikan hasil yang terbaik.

Tujuan penelitian ini adalah membangun aplikasi pengklasifikasian kualitas biji pinang berbasis android. Hanya fitur warna red, green dan blue (RGB) yang digunakan sebagai ciri pembeda. Algoritma klasifikasi yang digunakan adalah metode Nearest Mean Classifier (NMC). Aplikasi ini membantu proses klasifikasi biji pinang secara cepat dan akurat. Aplikasi ini diharapkan dapat diterima oleh petani maupun pembeli, sehingga dapat dijadikan alat ukur standar. Dengan demikian proses jual beli pinang lebih fair dan menguntungkan kedua belah pihak. 


\section{Tinjauan Literatur}

Pengetahuan tentang asal-usul tanaman pinang masih beragam. Namun demikian diperkirakan Pinang berasal dari daratan Asia seperti Malaya, India, Indonesia dan beberapa daerah di kepulauan Pasifik [5]. Luas area tanaman pinang di Indonesia pada tahun 2011 ditaksir 147.890 ha, dengan produksi 69.881 ton dan produktivitas rata-rata $743 \mathrm{~kg} /$ ha. Petani pinang umumnya mengolah buah pinang secara tradisional menjadi biji pinang kering. Berdasarkan hasil survey pada bulan Januari 2018, pemisahan biji pinang dilakukan dengan cara dibelah menggunakan pisau atau parang, dijemur, kemudian dicungkil dan dikeringkan baru dijual ke pengepul. Peningkatan produksi dan produktivitas biji pinang membuka lapangan kerja di pedesaan serta meningkatkan pendapatan petani dan ekspor. Pinang yang diekspor masih berupa bahan mentah, yaitu biji kering dalam bentuk biji utuh, biji belah maupun irisan kering. Biji pinang kering diekspor ke India, Pakistan, dan Bangladesh, dalam bentuk biji pinang belah atau utuh. Pada tahun 2008, volume ekspor pinang mencapai 182.972 ton, dengan nilai ekspor US\$106,33 juta. Pada tahun2009, volume ekspor pinang meningkat menjadi 197.197 ton [6]

Budidaya Pinang secara komersial awalnya hanya dilakukan di India, Bangladesh dan Sri Lanka. Sedangkan di Indonesia tanaman pinang tumbuh secara liar atau ditanam sebagai tanaman pekarangan, kecuali di beberapa daerah di Sumatera sebagian petani sudah mulai membudidayakan walaupun tidak dalam areal yang luas. Di Indonesia pada awalnya secara tradisi biji pinang digunakan sebagai stimulan, dicampur dengan sirih, kapur dan tembakau. Selanjutnya biji pinang kering digunakan sebagai bahan baku industri dan farmasi. Pada bidang farmasi digunakan sebagai campuran pembuat obat-obatan, seperti obat disentri, cacing, obat kumur dan bahkan sampai penyakit alzheimer [7]. Pinang juga berpeluang sebagai bahan makanan [2]. Pada bidang industri digunakan dalam penyamakan kulit, pewarna kain dan kapas [3].

Pengeringan biji pinang dilakukan dengan cara dijemur di bawah terik matahari. Pengeringan ini bertujuan untuk mengurangi volume dan berat produk [8]. Pengeringan juga dilakukan untuk mengurangi kadar air agar biji pinang lebih awet sehingga daya simpan menjadi panjang. Bagaimanapun juga kadar air turut mempengaruhi harga jual. Biasanya yang menjadi tolok ukur standar kadar air adalah persentase kadar air. Untuk mencapai kualitas standar tersebut penjemuran biasanya dilakukan selama 3 hari pada kondisi matahari terik. Indikator yang bisa dijadikan acuan dalam menentukan kelayakan tingkat kekeringan ini adalah dengan melihat secara kasat mata atau dengan melakukan pematahan biji pinang hasil penjemuran [9].

Ada beberapa penelitian state of the art pada bidang teknologi dan sistem informasi berkaitan dengan klasifikasi pinang dimana teknik pemrosesan citra digital digunakan. Penelitian Huang [10] yaitu pendeteksian dan pengklasifikasian pinang menggunakan machine vision. Fitur yang digunakan adalah warna red, green dan blue (RGB) dimana digunakan jaringan syaraf tiruan dalam proses klasifikasinya. Namun yang dideteksi adalah kualitas buah pinang dengan mengidentifikasi kulitnya bukan bijinya. Metode tersebut cukup efisien dengan rata-rata akurasi 90,9\%. Penelitian lainnya yaitu Danti dan Suresha [11] menggunakan model warna RGB kemudian ditransfer menjadi model warna YCBCR namun yang dilakukan adalah pendeteksian varietas dan penyakit pada biji pinang. Penelitian lainnya adalah pendeteksian kerusakan biji pinang menggunakan metode probabilistic neural network menggunakan fitur tekstur gray level co-occurence matrix (GLCM) yang cukup terbukti efisien dalam menentukan kerusakan biji pinang. Selain itu yang ada adalah riset yang membangun mesin pengupas pinang [12], mesin pemilah biji pinang atau mesin sortir biji pinang [4] [13][14][15].

Berdasarkan beberapa literatur di atas dapat diketahui bahwa penggunaan fitur warna red, green dan blue (RGB) dan fitur tekstur gray level co-occurence matrix (GLCM) memberikan hasil yang baik dan efisien dalam melakukan pendeteksian kualitas pinang. Algoritma yang digunakan adalah jaringan syaraf tiruan [10] untuk pendeteksian kualitas biji pinang, sedangkan k-nearest neighbor [4] dan support vektor machine [15] diaplikasikan untuk mesin sortir pinang. Namun demikian belum ada laporan penelitian terapan yang membangun aplikasi pendeteksian kekeringan biji pinang dengan memanfaatkan perangkat handphone android. Padahal seperti diketahui bahwa pada umumnya masyarakat memiliki handphone android yang dilengkapi dengan kamera. Hal ini akan menjadi sesuatu yang efektif dan efisien dalam membantu transaksi jual beli pinang yang fair antara petani dan pengepul. 


\section{Metode Penelitian}

Metode penelitian yang digunakan adalah eksperimen. Tujuan dari melakukan eksperimen adalah untuk menguji apakah sistem aplikasi yang diusulkan potensial digunakan oleh user. Untuk itu sistem ini dievaluasi yaitu dengan mengukur akurasinya.

Bahan yang digunakan dalam penelitian ini adalah: (1) Sejumlah biji pinang kering (telah dibelah dan dipisahkan dari kulitnya). Biji pinang tersebut dikategorikan ke dalam 3 kelas berdasarkan tingkat kekeringan, yaitu: biji pinang dengan kadar air dibawah 5\%,biji pinang dengan kadar air 5\%-12\%, dan biji pinang dengan kadar air diatas $12 \%$. Biji pinang tersebut, kemudian akan diambil citranya untuk pelatihan dan sejumlah biji pinang yang lain diambil citranya untuk pengujian. Tabel 1 dan Tabel 2 menampilkan data citra latih dan data citra uji, (2) Kamera ponsel pintar android merek Asus Zenfone 316 Mega Pixels. Semua citra ditangkap dengan ukuran 2.304 x 4.096 piksel. Citra tersebut kemudian disimpan dengan intensitas 24 bit (224=16 juta warna) atau biasa disebut true color, dimana masing-masing kanal RGB (red green blue) memiliki panjang 8 bit ( $28=256$ varian warna). (3) Sebuah tiang penyangga (tripod) agar pengambilan citra dapat dilakukan pada jarak yang sama. Intensitas pencahayaan saat pengambilan citra pada fase pembentukan kelas dan pada fase klasifikasi dibuat sama baik. (4) Sistem komputer yang digunakan terdiri dari perangkat lunak bahasa pemrograman Android Studio versi 2.3 dan sistem operasi windows 10 Home. Sedangkan untuk perangkat kerasnya adalah komputer dengan processor intel core i7generasi terbaru $4.1 \mathrm{GHz}$ dan RAM 32 GB.

Tabel 1 Data Citra Latih

\begin{tabular}{ccc}
\hline No. & Kelas & Jumlah \\
\hline 1 & Kelas A (kadar air $\leq 5 \%)$ & 10 \\
\hline 2 & Kelas B (kadar air 6\%-11\%) & 10 \\
\hline 3 & Kelas C (kadar air $\geq 12 \%)$ & 10 \\
\hline \multicolumn{2}{c}{ Total } & 30 \\
\hline
\end{tabular}

Tabel 2 Data Citra Uji

\begin{tabular}{ccc}
\hline No. & Kelas & Jumlah \\
\hline 1 & Kelas A (kadar air $\leq 5 \%)$ & 5 \\
\hline 2 & Kelas B (kadar air 6\%-11\%) & 5 \\
\hline 3 & Kelas C (kadar air $\geq 12 \%)$ & 5 \\
\hline & Total & 15 \\
\hline
\end{tabular}

Dalam membangun sistem pendeteksi tingkat kekeringan biji pinang adalah mengadopsi langkah-langkah penelitian Abdullah \& Ku-Mahamud [16] sebagaimana Gambar 2 yaitu: (1) merancang sistem; (2) menerapkan sistem; (3) melakukan eksperimen menggunakan citra yang sudah dikumpulkan; (4) mengukur akurasi sistem menggunakan matriks konfusi dan hold out; (5) terakhir, hasil eksperimen dievaluasi menggunakan analisis statistik.

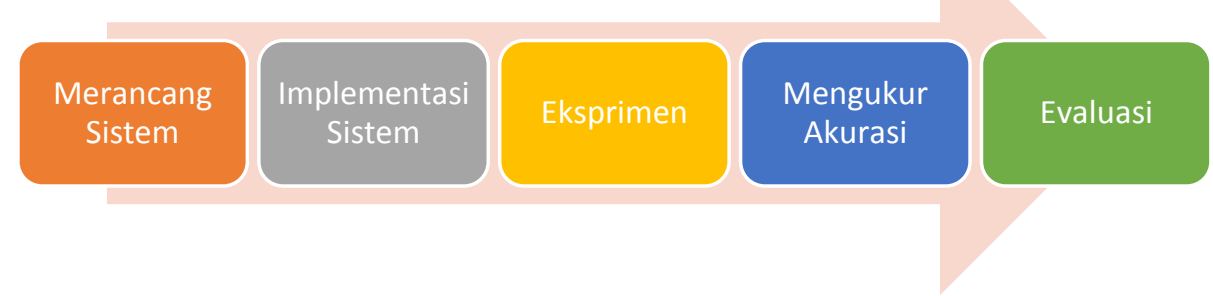

Gambar 2. Kerangka Kerja Penelitian

Aplikasi diharapkan mampu melakukan pendeteksian biji pinang dengan baik, namun tidak dapat dipungkiri bahwa kesalahan akan terjadi dalam proses pengklasifikasian tersebut sehingga perlunya dilakukan evaluasi aplikasi tersebut. Pengukuran kinerja sistem klasifikasi dilakukan dengan metode holdout [17] dan menggunakan matriks konfusi (confusion matrix) [18].

\section{Hasil dan Pembahasan}

\section{Rancangan Sistem}

Sistem dibagi menjadi 2 bagian yaitu subsistem pelatihan dan subsistem pengujian. Subsistem pelatihan berfungsi untuk menyimpan data base pengetahuan berupa data vektor fitur citra latih, yang berisi data warna red, green, blue dan label kualitas. Sedangkan subsistem pengujian merupakan hasil 
dari proses klasifikasi sistem, pada proses ini diperoleh nilai mean kelas fitur warna dan label kualitas biji pinang yang ingin diketahui. Pada tahap ini dibuat basis data vektor fitur citra latih yang merupakan tempat dimana semua hasil ekstraksi fitur warna red, green, blue serta label kualitas dari objek sampel disimpan. Basis data ini dapat disebut sebagai memori pengetahuan yang dimiliki oleh sistem berguna dalam proses klasifikasi. Proses klasifikasi sangat bergantung dengan adanya basis data vektor fitur citra latih karena pada basis data ini diperoleh nilai dari mean kelas.

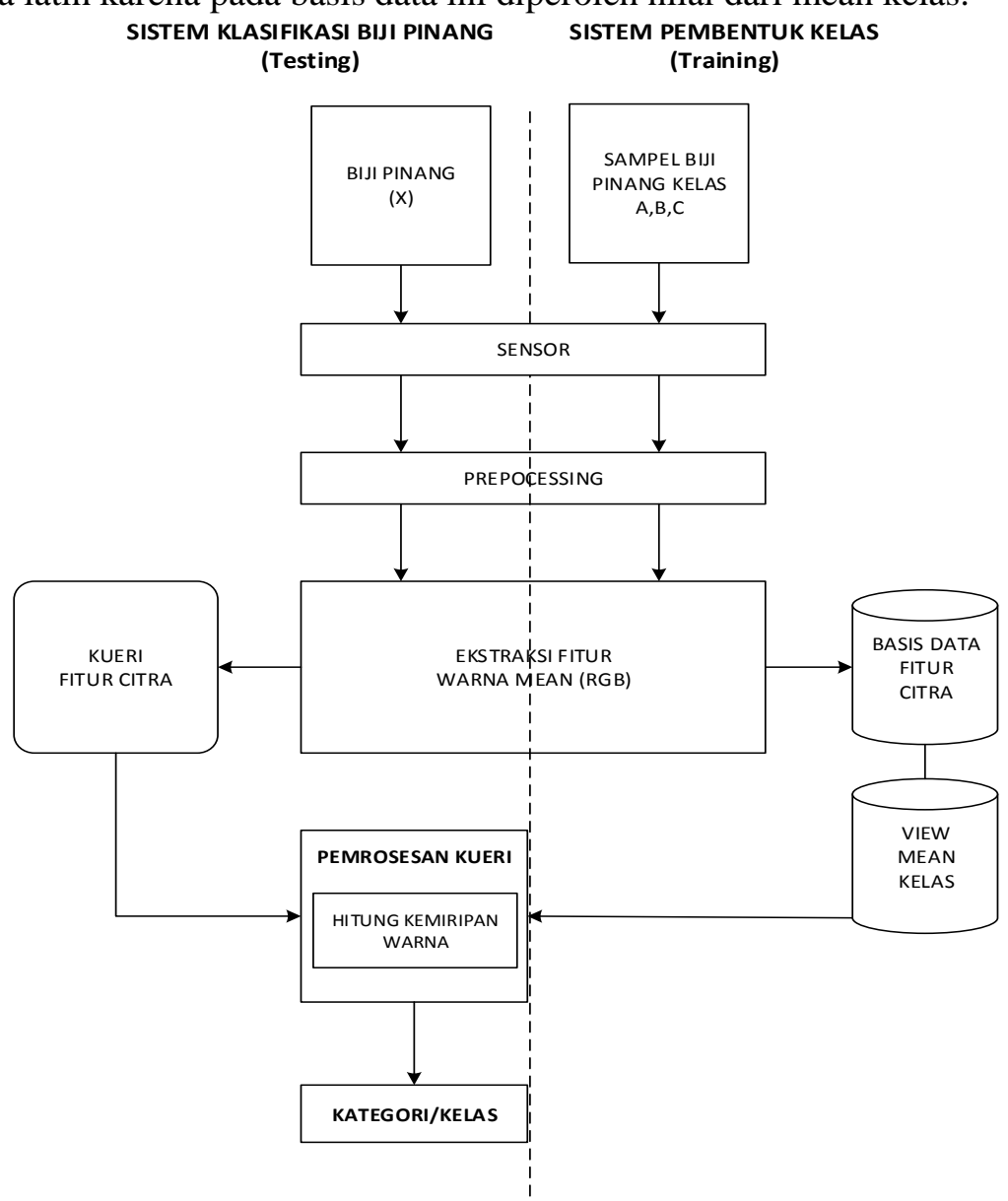

Gambar 3. Arsitektur Sistem Klasifikasi Biji Pinang

Proses yang digunakan dalam sistem ini (Gambar 3) terbagi menjadi dua proses yaitu sistem pembentuk kelas (training) dan sistem klasifikasi biji pinang (testing). (1) Sistem pembentuk kelas merupakan tahapan awal dari sistem yang akan dibangun, pada proses ini memori sistem akan disimpan kedalam database dimana semua hasil ekstraksi fitur warna Red, Green, Blue serta label kualitas disimpan pada basis data. Kemudian dibuat mean kelas untuk masing-masing kualitas biji pinang yang telah melalui tahap pelatihan sampel. (2) Sistem klasifikasi biji pinang dilakukan dengan cara mencari kemiripan antara objek citra yang akan diketahui kualitasnya dengan objek yang ada pada database. Penentuan dilakukan dengan menghitung jarak euclidean antara vektor fitur citra yang dideteksi dengan vektor fitur pada tabel view mean kelas yang diturunkan dari basis data vektor fitur citra. Semakin kecil jarak antara objek yang dideteksi dengan objek pada basis data maka kemiripan semakin besar begitupun sebaliknya semakin besar jarak antara objek yang dideteksi dengan objek pada basis data maka kemiripan semakin kecil.

Gambar 4 menunjukkan rancangan tampilan Sistem. Untuk mencari kemiripan antara objek queri yang ingin diketahui kualitasnya dihitung dengan perhitungan jarak euclidean terhadap nilai mean kelas yang ada pada database pengetahuan. 


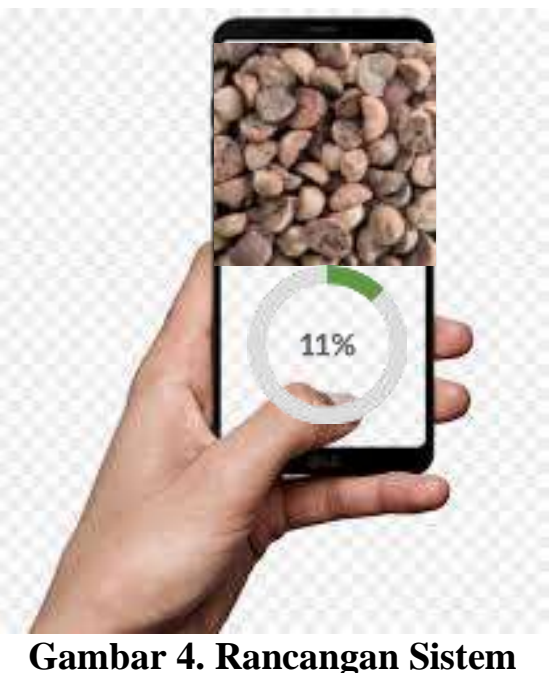

\section{Implementasi Sistem}

Sistem klasifikasi biji pinang yang dibangun dibuat menggunakan bahasa pemrograman java dengan aplikasi penunjang Android Studio versi 3.0 dengan minimal sistem operasi android Kitkat 4.2 yang di uji dengan ponsel android asus zenfone 3 dengan sistem operasi android 8.0 (Oreo). Gambar 5 menampilan hasil implementasi pada saat pengujian kualitas biji pinang. Gambar 6 memberikan informasi kandungan kadar air, dan klasifikasi kualitas biji pinang.

Sistem yang dibangun akan diuji menggunakan evaluasi holdout. Holdout merupakan metode evaluasi yang menyediakan sejumlah data untuk digunakan sebagai data testing dan sisanya data training. Pembagian data training-testing yang umum digunakan adalah dengan metode holdout yang membagi sebagian data untuk data testing dan sisanya untuk data training. Setiap dataset harus dipilih secara independent. Namun pembagian ini tidak menjamin bahwa data testing atau data training memiliki representative dari setiap kelas yang ada. Oleh karena itu, diperlukan sebuah prosedur dimana data training dan data testing harus memiliki representative untuk semua kelas (Utami \& Ulama, 2015)

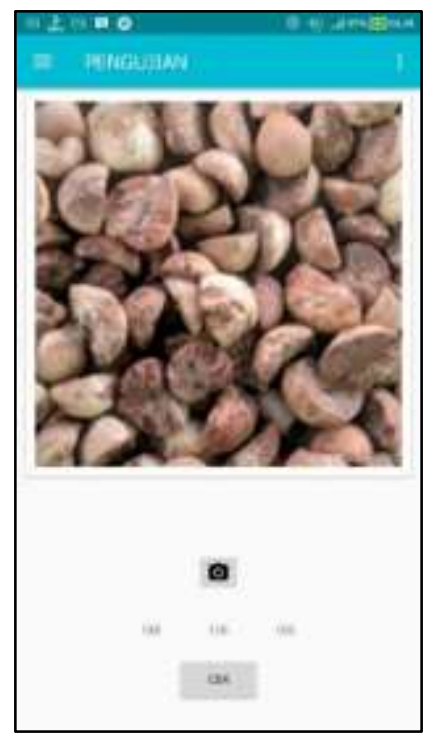

Gambar 5.Proses Penentuan Nilai RGB

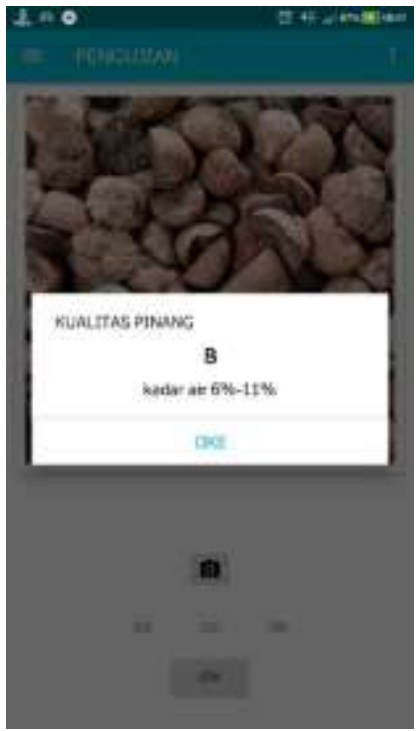

Gambar 6 Hasil Uji Kualitas Biji Pinang 


\section{Eksperimen}

Berikut merupakan hasil eksperimen disimpan dalam basis data sistem yang dibangun:

Tabel 3. Basis data Vektor Fitur Citra Latih

\begin{tabular}{ccccc}
\hline Id & R & G & B & Kualitas \\
\hline 1 & 153 & 125 & 108 & A \\
\hline 2 & 146 & 121 & 104 & A \\
\hline 3 & 152 & 125 & 108 & A \\
\hline 4 & 149 & 123 & 106 & A \\
\hline 5 & 147 & 120 & 104 & A \\
\hline 6 & 150 & 122 & 106 & A \\
\hline 7 & 145 & 119 & 103 & A \\
\hline 8 & 148 & 121 & 105 & A \\
\hline 9 & 144 & 119 & 102 & A \\
\hline 10 & 143 & 119 & 103 & A \\
\hline 11 & 155 & 120 & 106 & B \\
\hline 12 & 152 & 120 & 107 & B \\
\hline 13 & 153 & 121 & 105 & B \\
\hline 14 & 152 & 121 & 106 & B \\
\hline 15 & 151 & 121 & 105 & B \\
\hline & & & &
\end{tabular}

\begin{tabular}{ccccc}
\hline Id & R & G & B & Kualitas \\
\hline 16 & 154 & 123 & 109 & B \\
\hline 17 & 153 & 122 & 108 & B \\
\hline 18 & 160 & 127 & 112 & B \\
\hline 19 & 153 & 119 & 105 & B \\
\hline 20 & 143 & 112 & 98 & B \\
\hline 21 & 136 & 116 & 98 & C \\
\hline 22 & 132 & 113 & 95 & $\mathrm{C}$ \\
\hline 23 & 127 & 107 & 90 & $\mathrm{C}$ \\
\hline 24 & 130 & 112 & 94 & $\mathrm{C}$ \\
\hline 25 & 131 & 110 & 94 & $\mathrm{C}$ \\
\hline 26 & 136 & 117 & 98 & $\mathrm{C}$ \\
\hline 27 & 133 & 112 & 94 & $\mathrm{C}$ \\
\hline 28 & 132 & 113 & 95 & $\mathrm{C}$ \\
\hline 29 & 132 & 111 & 93 & $\mathrm{C}$ \\
\hline 30 & 135 & 115 & 96 & $\mathrm{C}$ \\
\hline
\end{tabular}

Pada Tabel 3 basis data vektor fitur citra latih dapat dilihat semua memori basis pengetahuan yang dimiliki oleh sistem yang dibangun terdiri dari nomor id, nilai $R$, nilai $G$, nilai B dan label kualitas yang diberikan pada setiap objek sampel yang telah dilatih. Semua memori basis pengetahuan ini kemudian akan menjadi acuan dalam proses klasifikasi.

\section{Pengujian}

Evaluasi ini dilakukan pengujian sebanyak 10 kali. Validasi dilakukan dengan menggunakan holdout dengan membagi dataset yang berjumlah total 45 menjadi 30 data training dan 15 data testing. Akurasi dihitung ketika jumlah data yang diklasifikasi secara benar maupun salah diketahui, dengan bantuan matriks konfusi (confusion matrix) [18]. Pengujian ini mendapatkan nilai rata-rata akurasi dan simpangan baku dari sistem. Tabel 4 menunjukkan hasil pengujian.

Tabel 4. Rata-rata Akurasi Pengujian

\begin{tabular}{ccc}
\hline Pengujian & Data Training-Testing & Akurasi \\
\hline 1 & $30-15$ & $73,3 \%$ \\
\hline 2 & $30-15$ & $86,6 \%$ \\
\hline 3 & $30-15$ & $86,6 \%$ \\
\hline 4 & $30-15$ & $86,6 \%$ \\
\hline 5 & $30-15$ & $73,3 \%$ \\
\hline 6 & $30-15$ & $73,3 \%$ \\
\hline 7 & $30-15$ & $66,6 \%$ \\
\hline 8 & $30-15$ & $86,6 \%$ \\
\hline 9 & $30-15$ & $86,6 \%$ \\
\hline 10 & $30-15$ & $80,0 \%$ \\
\hline Rata-rata Akurasi & & $\mathbf{8 0 , 0} \%$ \\
\hline Simpangan Baku & & $\mathbf{7 , 6 \%}$ \\
\hline
\end{tabular}

Berdasarkan pengujian di atas dapat diketahui bahwa pengujian menggunakan metode holdout dari data eksperimen memiliki tingkat ketelitian sebesar 80\% dengan simpangan baku 7,6. 


\section{Kesimpulan}

Berdasarkan penelitian yang telah dilakukan dapat ditarik kesimpulan bahwa proses klasifikasi biji pinang dapat dilakukan oleh sebuah aplikasi dengan menggunakan algoritma Nearest Mean Classifier dengan memanfaatkan kamera dari smartphone berbasis android. Berdasarkan hasil evaluasi diketahui tingkat akurasi metode Nearest Mean Classifier dalam menentukan kualitas biji pinang adalah sebesar $80 \%$ dengan simpangan baku 7,6. Untuk meningkatkan kinerja prediksi kualitas biji pinang disarankan dengan menambahkan fitur tekstur dan penambahan koreksi cahaya dalam penangkapan objek biji pinang agar tingkat akurasi menjadi lebih baik.

\section{Referensi}

[1] F. D. Korwa, J. Husain, T. Titah, and J. Supit, "Evaluasi Kesesuaian Lahan untuk Tanaman Pinang (Areca catechu) di Das Remu, Sorong, Papua Barat," J. Cocos, vol. 7, no. 4, pp. 1-8, 2015.

[2] R. Barlina, "Peluang Pemanfaatan Buah Pinang untuk Pangan Opportunity of Arecanut for Food Utilizing," Bul. Palma, vol. 33, pp. 96-105, 2007.

[3] I. D. G. P. Prabawa, "Ekstrak Biji Buah Pinang Sebagai Pewarna Alami pada Kain Sasiringan," J. Ris. Ind. Has. Hutan, vol. 75, no. 2, pp. 31-38, 2015.

[4] P. Hartono and Trismiyati, "Klasifikasi Biji Pinang Belah pada Pengembangan Mesin Sortir Pinang menggunakan Pengolahan Citra Digital," J. Ris. Ind., vol. 10, no. 2, pp. 61-69, 2016.

[5] Miftahorrachman, "Diversitasi Genetik Tujuh Aksesi Plasma Nutfah Piang (Areca catechu L.) Asal Pulau Sumatera," J. LITTRI, vol. 12, no. 1, pp. 27-31, 2006.

[6] Balai Penelitian Tanaman Palma, "Prospek Pengembangan Tanaman Pinang," Warta Penelitian dan Pengembangan Pertanian, vol. 34, no. 1, pp. 10-11, 2012.

[7] S. K. Bhat, D. Ashwin, S. Mythri, and S. Bhat, "Arecanut ( Areca catechu L ) decreases Alzheimer's disease symptoms: Compilation of research works," J. Med. Plants Stud., vol. 5, no. 5, pp. 4-9, 2017.

[8] E. Y. Kartika, "Penentuan kadar air dan kadar abu pada biskuit," J. Kim. Anal., vol. 2, pp. 1-10, 2014.

[9] N. H. Kario, "Analisis Usaha Panen Cengkeh di Kabupaten Minahasa Tenggara Propinsi Sulawesi Utara," J. Agritech, vol. XVI, no. 2, pp. 146-156, 2014.

[10] K. Huang, "Detection and classification of areca nuts with machine vision," Comput. Math. with Appl., vol. 64, no. 5, pp. 739-746, 2012.

[11] A. Danti and Suresha, "Segmentation and Classification of Raw Arecanuts Based on Three Sigma Control Limits," Procedia Technol., vol. 4, September, pp. 215-219, 2012.

[12] K. Kran, A. K. Govin, M. Bandi, and Shivasharanayya, "Design, Development and Testing of an Areca nut Dehusking Agri-machine," Int. J. Eng. Res. Appl., vol. 4, no. 7, pp. 109-115, 2014.

[13] M. N. Fauzi and Mahaputra, "Rncang Bangun Mesin Pemilah Biji Pinang (Sorting Betel Nut Machine Design Building)," J. Ris. Teknol. Ind., vol. 9, no. 2, pp. 157-166, 2015.

[14] B. S. Ajith, B. C. Pramod, Y. D. Impha, H. S. Rakshith, K. Sudeep, and P. Padavu, "Modelling, Fabrication and Automation of Areca Nut Sorting Machine," J. Mech. Eng. Autom., vol. 7, no. 4, pp. 99-102, 2017.

[15] J. U. Bailoor, M. C. Sunny, K. R. Anchan, M. J. Tauro, and G. Shetty, "Segregation of Cashew Kernel and Areca Nut by Using Advanced Color Sorting Mechanism," Int. J. Sci. Dev. Res., vol. 3, no. 5, pp. 566-572, 2018.

[16] Abdullah, "Ant-based feature decomposition Method in constructing NMC and NBC ensembles," Int. J. Comput. Trends Technol., vol. 30, no. 1, pp. 46-49, 2015.

[17] S. Raschka, Model Evaluation, Model Selection, and Algorithm Selection in Machine Learning. 2018.

[18] P. Thomas, H. Bril El Haouzi, M. C. Suhner, A. Thomas, E. Zimmermann, and M. Noyel, "Using a classifier ensemble for proactive quality monitoring and control: The impact of the choice of classifiers types, selection criterion, and fusion process," Computers in Industry. 2018. 